\title{
Removal of the antibiotic levofloxacin (LEVO) in water by ozonation and $\mathrm{TiO}_{2}$ photocatalysis
}

\author{
Deniz Nasuhoglu, Angela Rodayan, Dimitrios Berk, Viviane Yargeau* \\ Department of Chemical Engineering, McGill University, 3610 University Street, Wong Building, H3A 2B2 Montreal, Quebec, Canada
}

\section{A R T I C L E I N F O}

\section{Article history:}

Received 23 September 2011

Received in revised form 3 February 2012

Accepted 6 February 2012

\section{Keywords:}

Levofloxacin

Photolysis

Photocatalysis

Antibacterial activity

\begin{abstract}
A B S T R A C T
Removal of the fluoroquinolone antibiotic levofloxacin (LEVO) was studied in two oxidation processes: photocatalysis (UVC lamp $\left.(254 \mathrm{~nm}), \mathrm{TiO}_{2}\right)$ and ozonation. $\mathrm{LEVO}\left(C_{0}=20 \mathrm{mg} / \mathrm{L}\right.$ ) was no longer detected after an ozone dose of $20.5 \mathrm{mg} / \mathrm{L}$ and after $180 \mathrm{~min}$ of photocatalytic oxidation. COD removals of $59 \%$ and $70 \%$ were measured for $270 \mathrm{mg} / \mathrm{L}$ of transferred ozone dose and $300 \mathrm{~min}$ of photocatalytic oxidation, respectively. Extensive treatment with ozone did not result in further reduction in COD levels reaching a plateau at the above mentioned value, however increased irradiation time led to increased COD removal during photocatalytic treatment. Both treatment methods proved to be effective ways of removing antibacterial activity. From agar diffusion test with Escherichia coli, it was observed that a transferred ozone dose of at least $20.5 \mathrm{mg} / \mathrm{L}$ and $180 \mathrm{~min}$ of irradiation were enough to completely remove antibacterial activity. Both treatments methods were shown to efficiently remove LEVO and its antibacterial activity and show promising results as possible applications for removal of antibiotics in wastewater.
\end{abstract}

(C) 2012 Elsevier B.V. All rights reserved.

\section{Introduction}

The risk associated with pharmaceuticals in the environment is a rising issue of global concern as significant amounts have been detected up to $\mu \mathrm{g} /$ L levels in the aquatic environment [1]. After their use, these substances are usually excreted only partially metabolized and end up in the sewage system. A great portion of these compounds is not removed by conventional sewage and wastewater treatment plants and is eventually discharged into receiving water [2]. Several of them are antibiotics that were demonstrated to lead to increased antibiotic-resistant pathogens in wastewater $[3,4]$ and potentially in receiving streams. Recent work also demonstrated that mixtures of various antibacterial classes can exert unexpectedly high levels of algal growth inhibition at individual concentration levels on the order of $1 \mu \mathrm{g} / \mathrm{L}$ [5].

Levofloxacin (LEVO) is a more recently developed antibiotic belonging to the fluoroquinolones (FQs) which are synthetic broad spectrum antibiotics. The first and second generation quinolones are active against gram-negative bacteria whereas the third and fourth generation quinolones have extended activity against grampositive bacteria as well. Ciprofloxacin belonging to the 2nd generation was the mostly prescribed quinolone in Europe in 2003. Currently the prescription trend is shifting towards levofloxacin and moxifloxacin both of which are 3rd generation quinolones [6].

\footnotetext{
* Corresponding author. Tel.: +1 514398 2273; fax: +1 5143986678 .

E-mail address: viviane.yargeau@mcgill.ca (V. Yargeau).
}

There are limited reports on the presence of LEVO in aquatic environments; however other FQs such as ofloxacin and ciprofloxacin were commonly detected in effluents of hospital wastewaters, sewage and wastewater treatments plants at $\mu \mathrm{g} / \mathrm{L}$ levels [7-9]. The biodegradability of quinolones was shown to be very low [10] thus making conventional biological treatment methods ineffective for their removal. Due to the fact that multiple FQs are commonly found to occur within wastewater matrices $[5,8]$ the total biological activity associated with all such compounds is considerably higher than the activity attributable to a single compound. Within a typical wastewater treatment facility, conventional wastewater treatment will result in prolonged exposure of wastewater-borne bacteria to significantly higher FQ concentrations than are present in wastewater effluents. Prolonged exposure of bacterial communities to an antibacterial compound is a condition which can result in evolution of low-level antibacterial resistance in affected bacterial communities $[11,12]$. Therefore, it is necessary to propose efficient treatment methods to transform these antibiotic agents to non-toxic, pharmaceutically less active or more biodegradable species.

Oxidation processes (OPs) have received great interest in the recent years as alternative or complementary methods to conventional wastewater treatment to prevent the release of these compounds into aquatic environments. Among these OPs; ozonation [13-15]; fenton and photo-fenton oxidation [16]; photolysis and $\mathrm{H}_{2} \mathrm{O}_{2}$ enhanced photolysis $[17,18]$; heterogenous photocatalysis $[19,20]$ were frequently studied. During advanced oxidation of pharmaceutical compounds, intermediate compounds are formed 
that might show more toxic effects than the parent compound [21]; therefore the overall goal of treatment processes should be the transformation into non-toxic or biologically less active products rather than just the removal of the parent compounds.

Reports on the advanced oxidation of relatively older FQs such as ofloxacin and ciprofloxacin are abundant [22-30]; however advanced oxidation of LEVO has seldom been investigated. The main results on ozonation of LEVO were very recently published [31] and only few other papers report the fate of this compound during UV radiation under close to sunlight conditions [32,33]. There is only one study in literature on photocatalytic removal of LEVO under UVA radiation [34] reporting reaction rate constants for reactions of LEVO with hydroxyl radicals and hydrated electrons and proposing reaction pathways. There are no reports on photocatalytic degradation of this compound under UVC radiation and no data on residual antibacterial activity during the any type of photocatalytic treatment of LEVO. Considering that UVC radiation is commonly used as a disinfection method for a variety of water treatment facilities, that possible synergistic effects can arise from coupling UVC radiation with $\mathrm{TiO}_{2}$ and that absorption spectra of LEVO [32] show significant absorption in the UVC range, it is essential to fill that knowledge gap and determine the fate of LEVO during photocatalytic treatment based on UVC radiation.

The focus of the work presented here was to show the applicability of ozonation and UVC photocatalysis towards removal of LEVO in aqueous systems. The simultaneous study of performances of ozonation and UVC photocatalysis towards the removal of LEVO also allowed for the first time to compare the efficiency of these oxidation techniques for the removal of this compound. During both advanced oxidation methods the evolution of generated products was monitored and the corresponding residual antibacterial activity was investigated. COD removal during treatment was used as a way of comparing mineralization capacity of both processes. Finally combination of ozonation followed by photocatalysis treatment was used to investigate the resistance of transformation products towards reaction with ozone and other oxidizing species formed during photocatalysis (e.g. hydroxyl radicals, superoxides or holes). In addition to providing knowledge on the fate of LEVO during ozonation and photocatalysis, this work also provided insight on the applicability of this type of treatment as a pretreatment step to industrial or hospital wastewater before their discharge to municipal treatment facilities to minimize the exposure of bacteria community to antibiotics and mitigate the risks of developing resistant bacteria.

\section{Materials and methods}

\subsection{Reagents}

Levofloxacin $\left(\mathrm{C}_{18} \mathrm{H}_{20} \mathrm{~N}_{3} \mathrm{O}_{4} \mathrm{~F}\right.$, >98\%) and sodium dihydrogen phosphate were obtained from Sigma-Aldrich, Canada. Aqueous stock solution ( $20 \mathrm{mg} / \mathrm{L}$ LEVO) was prepared in reverse osmosis (RO) water and kept at $4{ }^{\circ} \mathrm{C}$ in the dark until the time of treatment (maximum time of storage was one week). Initial pH of the solution was 6.5 and no buffer was added during the treatment of samples. Commercial $\mathrm{TiO}_{2}$ Degussa P25 (70\% anatase and 30\% rutile) was used as catalyst with an average particle size of $30 \mathrm{~nm}$ and BET surface area of $50 \mathrm{~m}^{2} \mathrm{~g}^{-1}$, according to the manufacturer. HPLC grade methanol, acetonitrile and isopropanol were purchased from Fisher Scientific, Canada. All the chemicals were used as received without purification.

\subsection{Ozonation setup}

Ozonation experiments were carried out in a 2-L acrylic reactor (600 $\mathrm{mm}$ height, $70 \mathrm{~mm}$ diameter) with continuous supply of an ozone-oxygen gas mixture to the bottom of the reactor containing $500 \mathrm{~mL}$ of LEVO solutions at a concentration of $20 \mathrm{mg} / \mathrm{L}$. Ozone was produced by an OZO-4VTT (Ozomax) at a rate of $3.3 \mathrm{~g} / \mathrm{h}$, using oxygen as a feed gas, and the $\mathrm{O}_{3} / \mathrm{O}_{2}$ gas was bubbled through a porous stainless steel diffusion plate (Mott Corporation, $2 \mu \mathrm{m}$ ) located at the bottom center of the ozonation column. Ozonation experiments were run for various times so that different doses could be applied (and thus transferred). The amounts of ozone fed to the system and leaving from the system per unit of time were measured using the standard iodometric titration (Standard Method \# $2350 \mathrm{E}$ ). The rate of ozone transfer into the solution was calculated as the difference between the amounts fed and leaving the system. All ozone doses reported here correspond to the ozone transferred to solution during experiments and are referred to as ozone dose $(\mathrm{mg} / \mathrm{L})$. It was observed that the presence of LEVO did not influence the rate of ozone transfer when compared to pure water. This indicated that the transfer of ozone to the solution was not affected by the reaction of ozone with dissolved constituents as observed in previous research [35]. Prior to ozonation all solutions were adjusted to a temperature of $17^{\circ} \mathrm{C}$ which corresponds to the average annual values for a typical wastewater treatment plant effluent in Quebec.

\subsection{Photocatalysis setup}

Irradiation experiments were carried out in 2-L capacity cylindrical acrylic photoreactor ( $215 \mathrm{~mm}$ height, $108 \mathrm{~mm}$ diameter). The reactor walls were covered with aluminum foil to avoid exposure to UV radiation. $1.6 \mathrm{~L}$ of an aqueous solution of LEVO $(20 \mathrm{mg} / \mathrm{L})$ was charged to the reactor for each experiment. The solution was irradiated by a $\mathrm{Hg}-\mathrm{Ar}$ (Germicidal UV-C) lamp (Atlantic Ultraviolet Corp. GPH212T5L) located in the center of the reactor and protected in a quartz sleeve (maximum output at $254 \mathrm{~nm}$ ) and mixing was achieved by magnetic stirring. Light intensity inside the reactor was measured by azoxybenzene actinometry. It was previously shown that light intensity inside the reactor varies highly with respect to the position inside the reactor and that the maximum intensity of incident radiation per unit volume measured was $1.3 \times 10^{-3} \pm 0.3$ einstein $/ \mathrm{min} / \mathrm{L}$ at a radial distance of $0.7 \mathrm{~cm}$ from the lamp and $10 \mathrm{~cm}$ from the bottom of the reactor [36]. For photocatalytic degradation experiments, a wide range of titanium dioxide concentrations of $0.05,0.2$ and $0.5 \mathrm{~g} / \mathrm{L}$ was chosen to be studied based on our previous work using the same reactor [36]. Before each experiment the required amount of titanium dioxide particles were suspended in RO water and sonicated for $30 \mathrm{~min}$ to reduce agglomeration and create a more stable suspension. In photolytic experiments no titanium dioxide was added to the reaction mixture.

In order to determine if the hydroxyl radicals contribute significantly to the removal of LEVO or if other oxidizing species generated during photocatalysis play a more important role, the effect of dissolved oxygen concentration and scavenging of hydroxyl radicals was investigated. Different concentrations of dissolved oxygen were obtained by continuously bubbling air $(8.8 \mathrm{mg} / \mathrm{L})$ or pure oxygen $(42 \mathrm{mg} / \mathrm{L})$ into the reaction mixture through a sparger located at the bottom of the reactor. For close to anoxic conditions, the dissolved oxygen in the reaction mixture was purged off by continuously bubbling nitrogen for $2 \mathrm{~h}$ before turning on the lamp and maintaining the flow of nitrogen through out the reaction time to obtain low dissolved oxygen levels $(0.5 \mathrm{mg} / \mathrm{L})$.

The method of scavenging and concentrations of scavenging compounds were based on results reported by Palominos et al. [19]. Isopropanol, described as one of the best hydroxyl radical quencher due to its high reaction rate constant with the radical $\left(1.9 \times 10^{9} \mathrm{~mol} / \mathrm{L} / \mathrm{s}\right)$ [37], was used in this work to scavenge the hydroxyl radicals. Isopropanol was added to the reaction mixture $\left(10 \mathrm{mg} / \mathrm{L} \mathrm{LEVO}\right.$ and $0.2 \mathrm{~g} / \mathrm{L} \mathrm{TiO}_{2}$ ) at a molar concentration which 
was three orders of magnitude larger than the initial concentration of LEVO.

\subsection{Analytical methods}

Prior to analysis, the collected samples were filtered using $0.22 \mu \mathrm{m}$ syringe filters. LEVO concentration was monitored by HPLC (Agilent 1200 series) equipped with a diode array detector set at a wavelength of $294 \mathrm{~nm}$. The ozonation and photocatalysis products were monitored at a wavelength of $225 \mathrm{~nm}$. The column used was Agilent Zorbax Eclipse Plus C-8 $(4.6 \mathrm{~mm} \times 150 \mathrm{~mm}, 3.5 \mu \mathrm{m})$. The eluents used were $15 \mathrm{mM}$ sodium dihydrogen phosphate at pH 2.6 (A) and acetonitrile (B). A gradient from 20\% B to 30\% over $10 \mathrm{~min}$ at a constant flow rate of $0.8 \mathrm{~mL} \mathrm{~min}^{-1}$ was employed. COD levels were monitored using a HACH Digital Reactor Block (DRB 200), a HACH spectrophotometer (DR/2500) and ultra low range (0-40 mg/L) COD digestion vials (HACH).

Agar diffusion tests were performed to evaluate the remaining antibacterial activity of LEVO after treatment by ozonation and photocatalysis. Strains of Escherichia coli (ATCC 1303) and Pseudomonas fluorescens (ATCC 13525) were inoculated onto nutrient agar. Ten milliliters aliquots were withdrawn from both the ozonation and/or the photocatalytic reactors at various reaction times. Filter papers (diameter of $8 \mathrm{~mm}$, Millipore $0.20 \mu \mathrm{m}$ GNWP04700) were soaked in these aliquots for $30 \mathrm{~s}$ and were placed in duplicates on to the bacteria inoculated agar plates. The plates were incubated for $24 \mathrm{~h}$ at $26^{\circ} \mathrm{C}$. Residual antibacterial activity of the samples was determined by measuring the inhibition diameter produced around the filter papers. The magnitude of the inhibition zone diameter was used as a semi-quantitative way to compare the efficiency of the oxidation processes studied at removing the antibiotic activity.

\section{Results and discussion}

\subsection{Removal of levofloxacin (LEVO) during photocatalysis}

Preliminary experiments were performed at an initial concentration of LEVO of $10 \mathrm{mg} / \mathrm{L}$ to determine the amount of photocatalyst that would lead to highest LEVO removal. Highest removal of LEVO after 10 min was achieved when the reaction mixture contained $0.2 \mathrm{~g} / \mathrm{L}$ of $\mathrm{TiO}_{2}$. Percentages of LEVO removed after 10 min of irradiation were $53.1 \pm 2.4 \%, 72.1 \pm 2.7 \%$ and $52.5 \pm 2.1 \%$ for $\mathrm{TiO}_{2}$ concentrations of $0.05,0.2$ and $0.5 \mathrm{~g} / \mathrm{L}$, respectively. The concentration of $\mathrm{TiO}_{2}$ observed for maximum removal of LEVO in the work presented here is lower when compared to other photocatalytic systems $[19,20,27-30]$; this can be explained by the larger diameter of the reactor employed. From our previous work [36], significant portion of the reactor was found to operate under UV dark indicating that only part of the volume of reactor participates in removal of the target compound since the $\mathrm{TiO}_{2}$ particles away from the lamp do not receive enough light. Increasing catalyst concentration above $0.2 \mathrm{~g} / \mathrm{L}$ leads to reduced removal rates since these high catalyst loadings lead to unfavourable light scattering and reduction of light penetration $[38,39]$. For the remainder of the photocatalytic experiments a concentration of $0.2 \mathrm{~g} / \mathrm{L}$ of catalyst was used.

Fig. 1 compares the performances of photolytic and photocatalytic removal of LEVO $\left(C_{0}=20 \mathrm{mg} / \mathrm{L}\right)$ for longer irradiation times. After 120 min of irradiation under photolysis (UVC) $65 \%$ of LEVO still remains in solution, however during photocatalysis after $120 \mathrm{~min}$ of reaction $97 \%$ of LEVO is removed and it is no longer detected at $180 \mathrm{~min}$ of irradiation. These results indicate that the photolytic removal of LEVO is not significant under UVC radiation. From the UV-vis absorption spectrum of LEVO (Supplementary material, Fig. S1) it is evident that this compound absorbs the

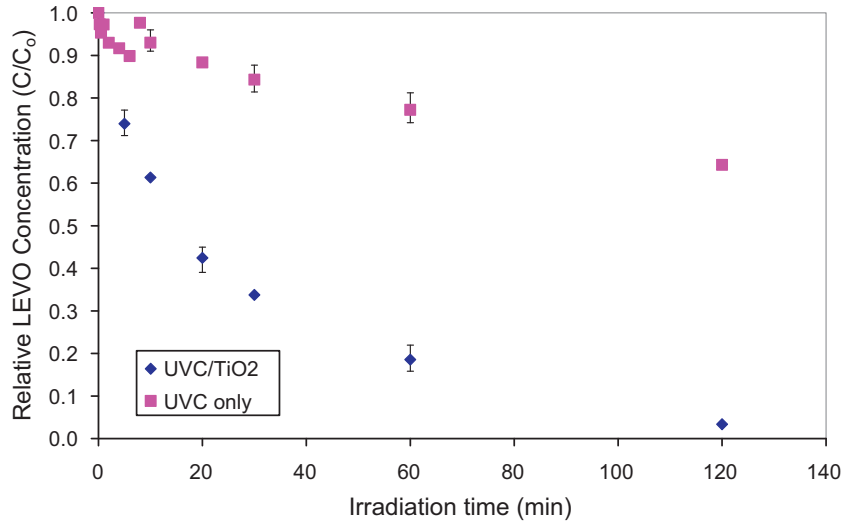

Fig. 1. Removal profiles of LEVO $\left(C_{0}=20 \mathrm{mg} / \mathrm{L}\right)$ with photolysis $\left(C_{\mathrm{TiO}_{2}}=0 \mathrm{~g} / \mathrm{L}\right)$ and photocatalysis $\left(C_{\mathrm{TiO}_{2}}=0.2 \mathrm{~g} / \mathrm{L}\right)$ for long irradiation times. Error bars $= \pm 1$ standard deviation.

most in the UVB range $(280<\lambda<315 \mathrm{~nm})$ with moderate absorption in the UVC $(\lambda<280 \mathrm{~nm})$ and UVA $(315<\lambda<400 \mathrm{~nm})$ ranges. Since the lamp used in the experiments operates in the UVC range, there is only slight photolytic removal of LEVO but the removal is enhanced when $\mathrm{TiO}_{2}$ is present due to generation of other oxidizing species. When using light sources operating at higher wavelengths $(\lambda>280 \mathrm{~nm})$, direct photolysis of LEVO may be more pronounced. Lam and Mabury [32] reported that 50\% of LEVO was removed within 20 min of irradiation when using a Xe lamp as the UV radiation source and radiation below $290 \mathrm{~nm}$ was cut off with filters. Significantly higher removal observed when working at higher wavelengths for LEVO suggests that its photolytic removal in the environment is possible; however the nature of the transformation products should be examined carefully to assess any remaining antibacterial activity.

\subsection{Removal of levofloxacin (LEVO) by ozonation}

Removal profile of LEVO by ozonation for an initial concentration of $20 \mathrm{mg} / \mathrm{L}$ is presented in Fig. 2. The rate of ozone transferred into the solution was determined from iodometric titrations to be $0.45 \mathrm{mg} / \mathrm{L} / \mathrm{s}$. It was found that after $20.5 \mathrm{mg} / \mathrm{L}$ of ozone was transferred into the solution, LEVO was no longer detected (corresponds to $45 \mathrm{~s}$ of continuous ozone bubbling). Furthermore, in order to remove $50 \%$ of the initial LEVO, $2.65 \mathrm{mg} / \mathrm{L}$ of $\mathrm{O}_{3}$ needs to be transferred into the solution, which corresponds to a half-life time for LEVO of $6 \mathrm{~s}$. When compared with the only data available on ozonation of LEVO in literature by Witte et al. [31], the half-life time

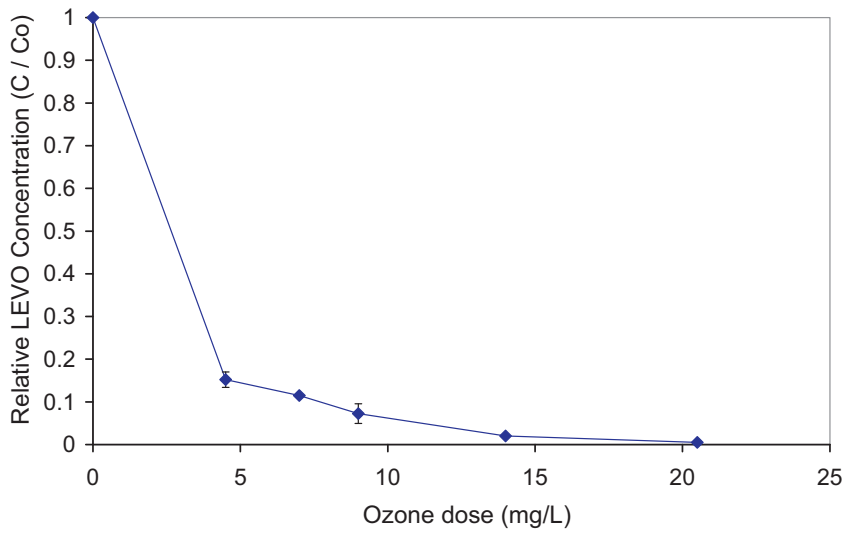

Fig. 2. Removal of $\operatorname{LEVO}\left(C_{0}=20 \mathrm{mg} / \mathrm{L}\right)$ as a function of ozone dose transferred. Error bars $= \pm 1$ standard deviation. 

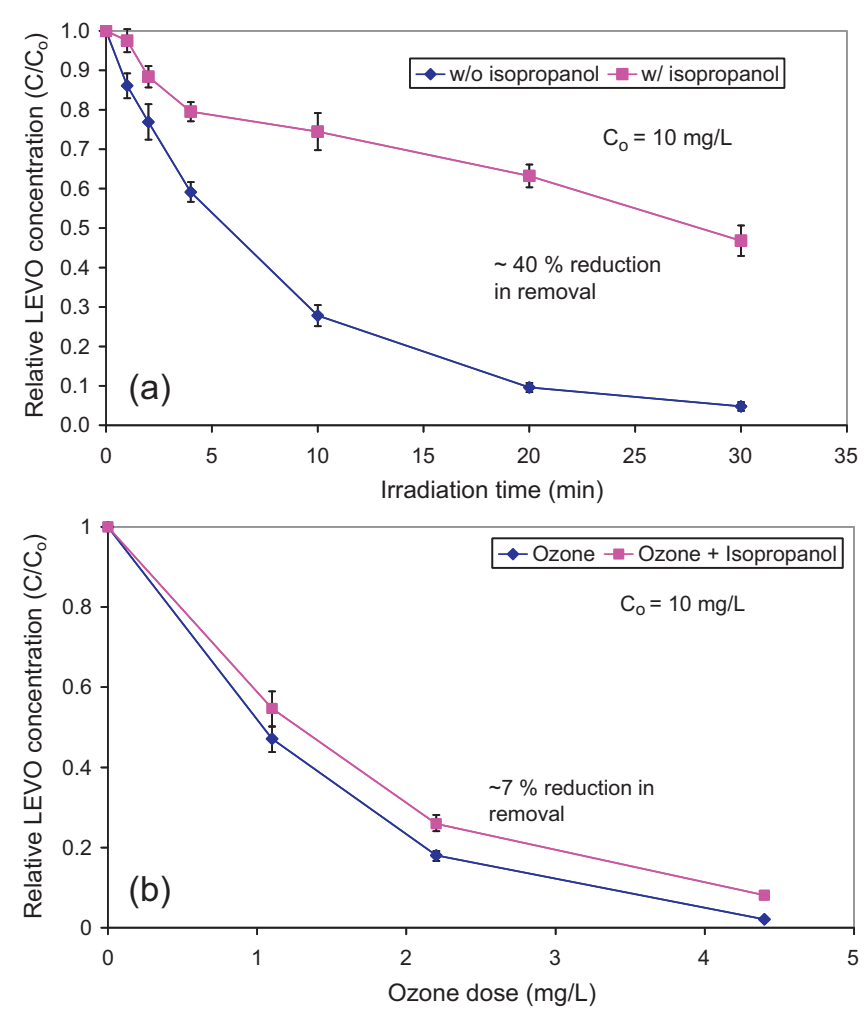

Fig. 3. Effect of the presence of hydroxyl radicals during (a) photocatalysis and (b) ozonation on removal of $\mathrm{LEVO}\left(C_{\mathrm{o}}=10 \mathrm{mg} / \mathrm{L}, C_{\mathrm{TiO}_{2}}=0.2 \mathrm{~g} / \mathrm{L}\right)$ studied by scavenging the hydroxyl radicals by addition of isopropanol. Errors bars $= \pm 1$ standard deviation.

observed here is about 80 times shorter than the reported value of $12.8 \mathrm{~min}$ (initial concentration of LEVO was $16.4 \mathrm{mg} / \mathrm{L}$ ). Witte et al. [31] reported an ozone consumption value of $0.61 \mathrm{mmol}$ during $60 \mathrm{~min}$ of reaction for a reaction volume of $1.75 \mathrm{~L}$. This value corresponds to an ozone transfer rate of $4.7 \mu \mathrm{g} / \mathrm{L} / \mathrm{s}$. This lower rate of ozone transfer, compared to our of $0.45 \mathrm{mg} / \mathrm{L} / \mathrm{s}$, explains the discrepancy in the half-life values reported here $(6 \mathrm{~s})$ and in the work of Witte et al. (12.8 $\mathrm{min}$ ) [31]. However, the calculated ozone dose corresponding to their reported half-life time is $3.6 \mathrm{mg} / \mathrm{L}$, which is in the same order of magnitude as the value of $2.65 \mathrm{mg} / \mathrm{L}$ reported above. The lower transfer rate they observed might be explained by the higher temperature they used, $27.5^{\circ} \mathrm{C}$, compared to the temperature of $17^{\circ} \mathrm{C}$ used here. The difference in temperature greatly influences the solubility of ozone leading to a reduction in transfer rate and higher half-lives. Other mass transfer limitation factors, such as gas retention time and bubble size may also explain this difference. Our results showed that ozonation can remove the target compound from the solution and emphasized the importance of mass transfer limitations in semi-continuous systems.

\subsection{Effect of hydroxyl radicals and dissolved oxygen concentration on removal of $L E V O$}

Participation of hydroxyl radicals on oxidation of LEVO during ozonation and photocatalysis was studied by addition of isopropanol. Results associated to scavenging of hydroxyl radicals are presented in Fig. 3a and b for photocatalysis and ozonation, respectively. Because previous work in our research group (unpublished) showed that addition of isopropanol during the ozone bubbling enhanced removal of pharmaceuticals due to increased mass transfer of ozone, scavenging experiments were carried out in batch mode. This phenomenon was also observed by De Witte et al. [24], where adding a t-butanol as a scavenger for hydroxyl radicals during continuous ozonation led to formation of smaller gas bubbles and increased mass transfer coefficient due to increased interfacial area. The stock solution of ozone was prepared by bubbling ozone in a glass-washing bottle containing reverse osmosis water to obtain a solution having an ozone concentration of $11 \mathrm{mg} / \mathrm{L}$. Required volume of the stock ozone solution was added to the LEVO-containing water to obtain three different ozone doses $(1.1 \mathrm{mg} / \mathrm{L}, 2.2 \mathrm{mg} / \mathrm{L}$ and $4.4 \mathrm{mg} / \mathrm{L}$ ). For scavenging experiments, isopropanol was added to the LEVO $\left(C_{0}=10 \mathrm{mg} / \mathrm{L}=2.8 \times 10^{-5} \mathrm{M}\right)$ containing water (at a concentration three orders of magnitude larger than the initial molar concentration of LEVO, $2.8 \times 10^{-2} \mathrm{M}$ ) prior to dosing with the ozone solution.

As evident from Fig. 3a addition of a scavenger during photocatalysis significantly inhibited the removal of LEVO. When no scavenger was present, $95 \%$ of LEVO was removed after $30 \mathrm{~min}$ of irradiation compared to $53 \%$ when the scavenger was present. This result suggests that the hydroxyl radicals contribute significantly to the removal of LEVO. Significant contribution of hydroxyl radicals on photocatalytic removal of fluoroquinolones under UVA radiation was demonstrated by An et al. [22,34], and Van Doorslaer et al. [40]. The work of Van Doorslaer et al. [40] also showed that contribution of photogenerated holes towards removal of moxifloxacin was more significant than hydroxyl radicals under UVA radiation. However, this could not be verified in our work because potassium iodide also absorbs considerable amount of radiation in the UVC radiation, thus distinction between oxidizing species scavenging effect and light reduction effect would not be possible. On the other hand, during ozonation (Fig. 3b) no significant inhibitory effects were observed when the scavenger was present (only $7 \%$ reduction in final removal). This result suggests that the main removal mechanism of LEVO during ozonation is due to direct reaction with ozone and that hydroxyl radicals play only a minor role in removal of the target compound. Dodd et al. [41] demonstrated that for fluoroquinolones the second reaction rate constants with hydroxyl radicals are significantly larger than rate constants with molecular ozone $\left(>2.2 \times 10^{5}\right.$ times). Based on the fact that scavenging of hydroxyl radicals do not lead to considerable deviation in the removal of LEVO during ozonation, it can be hypothesized that there is limited generation of hydroxyl radicals during the ozonation experiments. This can also be supported by the fact that the initial $\mathrm{pH}$ is 6.5 , after the instantaneous reaction with ozone, the $\mathrm{pH}$ drops to 4.8; at this point the generation of hydroxyl radicals would be limited. It has been shown that hydroxyl radicals are generated more at higher pH during ozonation [24].

The effect of the presence of hydroxyl radicals on removal of total organic content during photocatalysis was also studied by analyzing the UV-vis absorption spectra of samples with and without the addition of the scavenger. The results are shown in Fig. 4a and $\mathrm{b}$ as absorption spectra observed for various irradiation times. As irradiation time was increased up to 60 min treated samples showed considerably less UV absorption when no scavenger was present. Thus, it can be concluded that hydroxyl radicals are not only responsible for the removal of the target compound but also of the products generated during oxidation of LEVO during photocatalysis.

Effect of dissolved oxygen concentration on photocatalytic removal of LEVO was also studied. Removal of LEVO after $10 \mathrm{~min}$ of irradiation were measured for three different types of gases bubbled in the solution in order to vary the dissolved oxygen concentration. As expected, enhanced removal was achieved when pure oxygen was introduced into the system; removal of $91.6 \pm 3.3 \%$ of LEVO over $10 \mathrm{~min}$ of irradiation compared to $72.1 \pm 2.7 \%$ and $42.6 \pm 4.3 \%$ for air and nitrogen, respectively. The presence of oxygen reduces the recombination of electrons and holes generated upon irradiation of $\mathrm{TiO}_{2}$, thus allowing holes to either directly react with the target molecule or lead to generation of hydroxyl radicals as well as making it possible for super 

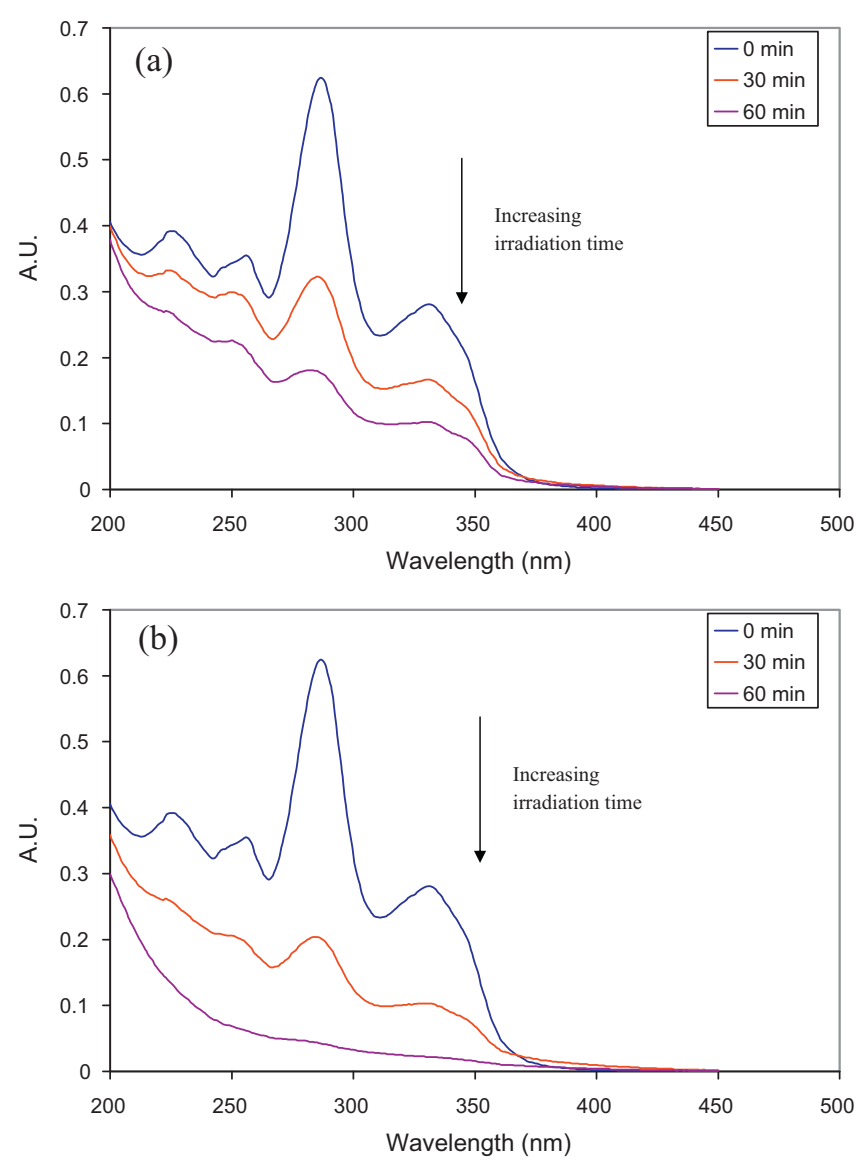

Fig. 4. UV-vis spectra during photocatalytic treatment of LEVO (a) with, (b) without the addition of hydroxyl radical scavenger isopropanol for various irradiation times $\left(C_{\mathrm{o}}=10 \mathrm{mg} / \mathrm{L}, C_{\mathrm{TiO}_{2}}=0.2 \mathrm{~g} / \mathrm{L}\right)$.

oxide molecules to be formed. When the system is purged with nitrogen, recombination of electrons and holes are enhanced thus leading to lower concentrations of oxidizing species to remove the target compound. The considerable reduction in the photocatalytic removal of another fluoroquinolone, moxifloxacin, when the system is sparged with pure nitrogen (instead of air or oxygen) was also demonstrated by Van Doorslaer et al. [40].

\subsection{Evolution of products and chemical oxygen demand (COD) removal}

During both photocatlysis and ozonation, the $\mathrm{pH}$ of the solution decreases with increased irradiation time or increased applied ozone dose (from pH 6.5 to 4.8 ). This suggests the generation and accumulation of acidic products. The evolution of the HPLC peak areas and the retention times of the major products detected are presented in Fig. 5a and b for photocatalysis and ozonation, respectively. During photocatalysis three of the five major products were removed from the system within $3 \mathrm{~h}$ of irradiation. For ozonation four of the six major products were removed when $55 \mathrm{mg} / \mathrm{L}$ of ozone were transferred into solution ( $2 \mathrm{~min}$ ). However, two products of ozonation were found at higher HPLC peak areas and were persistent towards further removal by ozone. These ozonation products were found to exist even after $10 \mathrm{~min}$ of ozonation $(270 \mathrm{mg} / \mathrm{L}$ of applied ozone). Even though considerably high peak areas were also detected for two of the products generated during photocatalysis, the evolution over time of their peak areas indicates that they are continuously being removed with increased irradiation time.
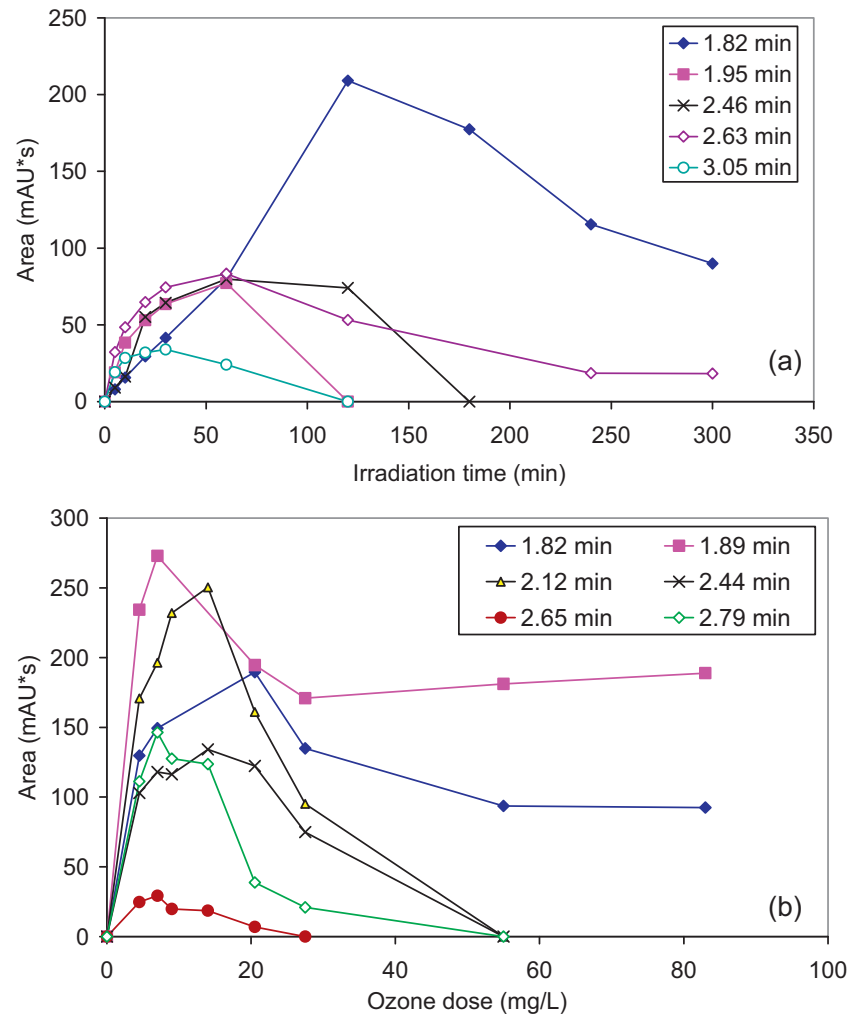

Fig. 5. HPLC peak area evolution of major product peaks detected at various retention times during (a) photocatalytic treatment, (b) ozonation of LEVO $\left(C_{0}=20 \mathrm{mg} / \mathrm{L}\right.$, $\left.\mathrm{C}_{\mathrm{TiO}_{2}}=0.2 \mathrm{~g} / \mathrm{L}\right)$.

These observations are in accordance with the chemical oxygen demand (COD) evolution results presented in Fig. 6a and b. For ozonation (Fig. 6a), the COD reduction is halted after an applied ozone dose of $55 \mathrm{mg} / \mathrm{L}$, corresponding to a maximum COD removal of $46-59 \%$ and suggesting that the organic matter is no longer being removed. On the other hand, the residual COD during the photocatalytic process started to monotonically decrease after $120 \mathrm{~min}$ of irradiation and reached $70 \%$ removal at 300 min (Fig. 6b). Hapeshi et al. [27] showed that for $20 \mathrm{mg} / \mathrm{L}$ of ofloxacin (racemic mixture of levofloxacin and its stereoisomer), UVA photocatalysis led to about $70 \%$ reduction in dissolved organic content (DOC) after $120 \mathrm{~min}$ whereas here UVC photocatalysis led to a reduction in COD of about $45 \%$ after $120 \mathrm{~min}$. The discrepancy can be attributed to the fact that Hapeshi et al. [27] used a much smaller reactor volume $(350 \mathrm{~mL})$ and the distribution of light was more homogenous leading to a larger portion of the reactor to be illuminated (i.e. more fraction of catalyst particles are illuminated leading to higher number of reactive radical species). Additionally, lower COD removal during ozonation compared to photocatalysis of another fluoroquinolone, ciprofloxacin, in hospital wastewater was also demonstrated by Vasconcelos et al. [42]. They showed that a maximum of $40 \%$ of initial COD was removed during heterogenous photocatalysis whereas this value was limited to only $10 \%$ for ozonation and enhanced ozonation did not lead to further decrease. Based on the previously published data for other compounds and on our results, it can be hypothesized that the active species generated during photocatalysis (e.g. hydroxyl radicals, superoxide radicals and holes) are less selective than ozone and react better with the transformation products. In order to investigate this hypothesis, ozonated samples of LEVO, collected after a transferred ozone dose of $20.5 \mathrm{mg} / \mathrm{L}$ in order to obtain a solution containing no residual LEVO but containing the ozonation transformation products, were subjected to photocatalysis. The COD removal for the combined ozonation/photocatalysis 

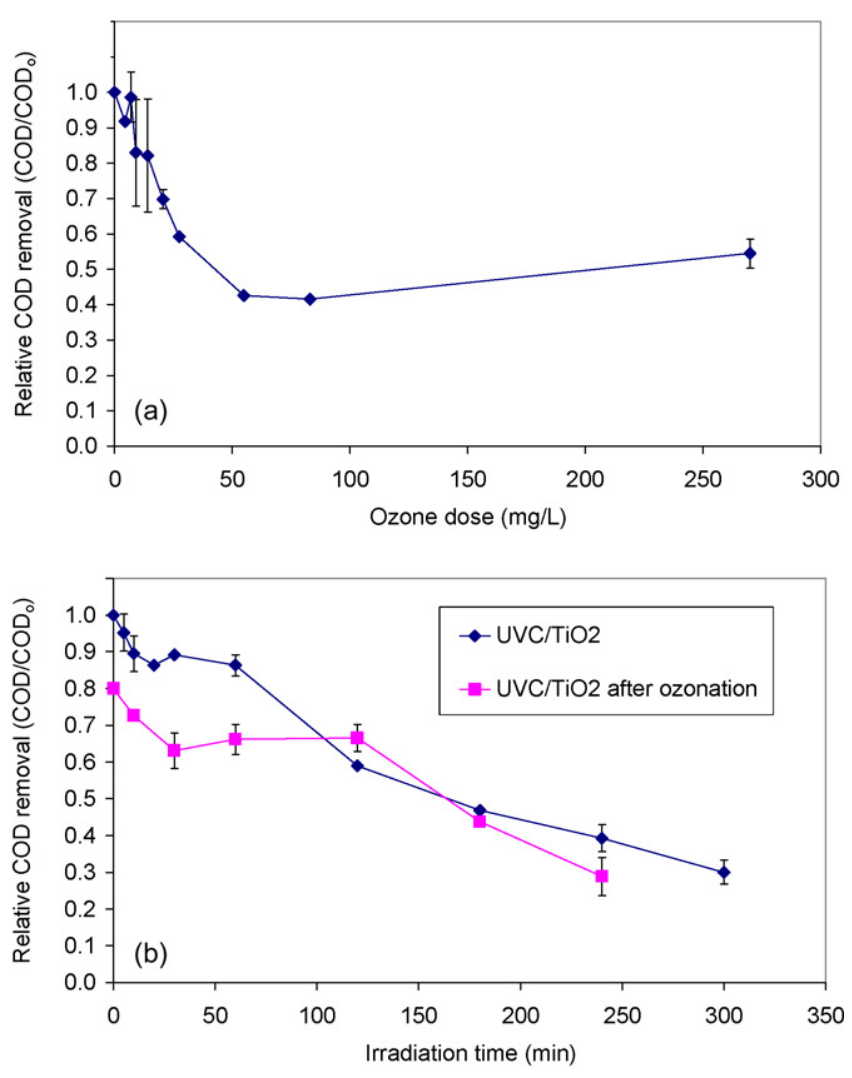

Fig. 6. COD removal during (a) ozonation, (b) photocatalysis and photocatalysis after ozonation. Error bars $= \pm 1$ standard deviation.

process is also presented in Fig. 6b. Since the LEVO was already removed by ozone when the photocatalytic treatment was started, the initial COD value was $80 \%$. With increased irradiation time, more COD was removed and again after 120 min of irradiation in the presence of $\mathrm{TiO}_{2}$, COD started to monotonically decrease. This indicates that the products generated during ozonation, which cannot be removed by additional amounts of ozone, can be removed by reaction with the oxidizing species present during photocatalysis. These results confirm that oxidative species formed during photocatalysis are less selective than ozone for oxidation of organic content and can then enhance the removal of the transformation products.

The products of ozonation and UVC photocatalysis for LEVO were not identified; however published data on removal of fluoroquinolones demonstrate that during ozonation, molecular ozone leads to the degradation in the piperazinyl substituent $[24,25,31,42]$. It is also hypothesized that due to the hydroxyl radical mediated reaction mechanism during ozonation (at $\mathrm{pH} 7$ ) removal of carbonyl and carboxyl groups at the quinolone moiety, essential for antibacterial activity, is achieved [25,31]. The scavenging results presented here for ozonation show that there is limited generation of hydroxyl radicals thus degradation at quinolone moiety is not expected for ozonation at the conditions studied. The major products generated from the photodegradation under UVA radiation of fluoroquinolones are due to the substitution of the fluorine substituent, the piperazine ring cleavage or the opening of quinolone ring following reactions with holes or hydroxyl radicals $[22,29,34]$. There is a need for further investigation into the nature of the UVC photocatalysis products of LEVO; however based on results obtained for other quinolones subjected to ozonation and UVA radiation, the ozonation products would most probably maintain an intact quinolone moiety while for products of UVC photocatalysis the quinolone ring might be inactivated.
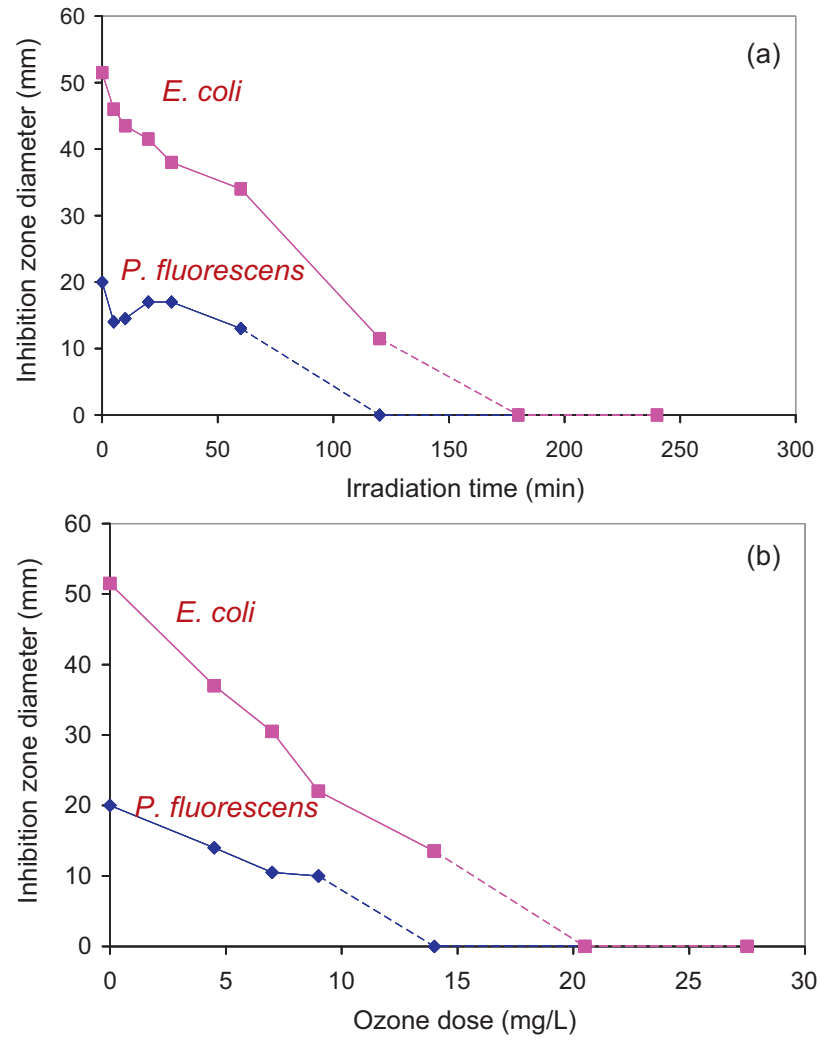

Fig. 7. Antibacterial activity measured as inhibition zone diameters from Agar diffusion tests during (a) photocatalytic treatment and (b) ozonation of LEVO $\left(C_{0}=20 \mathrm{mg} / \mathrm{L}\right)$ for E. Coli and P. Fluorescens.

\subsection{Residual antibacterial activity in treated solutions}

Even though both treatment methods were shown to completely remove LEVO, formation of organic species was observed. In order to assess the residual antibacterial nature of LEVO and its transformation products for each treatment type, agar diffusion tests were performed for E. coli and P. fluorescens. The inhibition zone diameters measured as a semi-quantitative indication of residual antibacterial activity are presented in Fig. 7a and b for photocatalysis and ozonation, respectively. For both photocatalysis and ozonation, the antibacterial activity was removed with increasing irradiation time and ozone dose, respectively. For treated solutions in which LEVO was no longer detected, the inhibition ring was barely measurable and reliable values were hardly obtained. As a result, the solid lines representing the data on Fig. 7a end when the minimum measurable zone diameter was observed. Pass that point, the dashed lines indicate that there might still be slight antibacterial activity whose magnitude could not be determined accurately. This observation can also be viewed on the photographs of the agar diffusion test plates shown in Fig. 8 for the photocatalytic treatment of LEVO. Similar observations were made for ozonation (images not presented). As observed on the $P$. fluorescens plate exposed to the solution after $120 \mathrm{~min}$ of irradiation, the slight inhibition observed is not measurable. However, for both organisms the antibacterial activity is completely removed after $180 \mathrm{~min}$ of irradiation since no inhibition halo is observed and the organisms clearly grew over the filter paper. The absence of antibacterial activity was considered obtained only when the microorganisms clearly grew over the placed filter papers. Considering that Paul et al. [29] showed that the antibacterial activity removal followed closely the fluoroquinolone removal even though a large number of photocatalysis products having an 
E. Coli

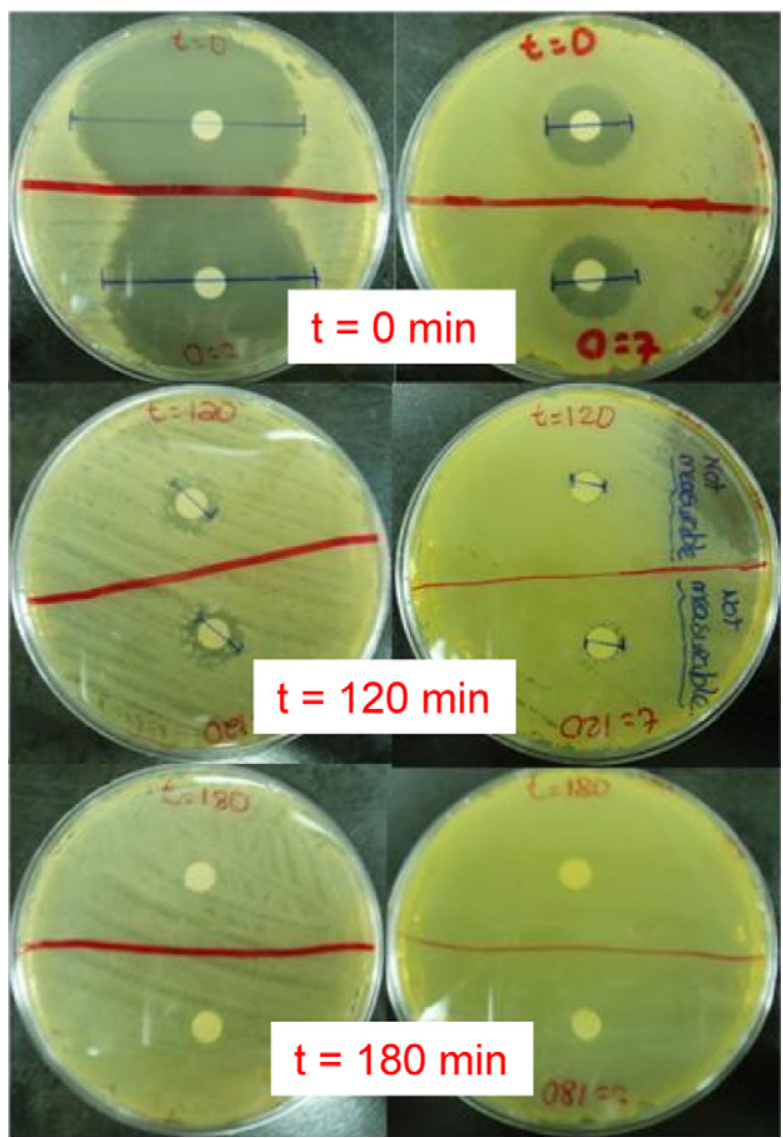

Fig. 8. Photographs of agar diffusion test plates during photocatalytic treatment of $\mathrm{LEVO}\left(C_{\mathrm{o}}=20 \mathrm{mg} / \mathrm{L}, C_{\mathrm{TiO}_{2}}=0.2 \mathrm{~g} / \mathrm{L}\right)$ at various irradiation times. Left hand side: $E$. coli Right hand side: P. Fluorescens.

intact quinolone moiety were present, the complete removal of the antibacterial activity as observed here, cannot be interpreted as an inactivation of the core quinolone structure of levofloxacin.

As observed from the inhibition zone diameters, E. coli shows more sensitivity to the presence of LEVO than $P$. fluorescens. For an initial concentration of $20 \mathrm{mg} / \mathrm{L}$ LEVO, there is at least $3 \mathrm{~cm}$ of difference in the inhibition zone diameters between $E$. coli and $P$. fluorescens. Looking at the plates of $E$. coli, transferred ozone dose of at least $20.5 \mathrm{mg} / \mathrm{L}$ and $180 \mathrm{~min}$ of irradiation were sufficient to remove completely antibacterial activity. In order to distinguish the antibacterial activity of products from the antibacterial activity of the parent compound, the agar diffusion tests were also performed on dilutions of LEVO with varying concentrations corresponding to the residual concentrations of LEVO in the treated samples. The measured inhibition zone diameters were normalized by the initial zone diameter observed for the untreated $20 \mathrm{mg} / \mathrm{L}$ of LEVO and defined as normalized inhibition zone diameter $\left(d / d_{0}\right)$. The values obtained were compared to those obtained for ozonation and photocatalysis in Fig. 9 but this time presented as a function of residual LEVO concentration as the abscissa to facilitate comparison. The untreated case refers to the samples that contain only LEVO at varying concentrations. All the data points for both treatments and for the untreated case scatter around a single curve indicating no observable difference between the treatment methods and the diluted LEVO samples. This suggests that for the two organisms studied the antibacterial activity is only related to the parent compound (LEVO) and that the generated products (transient or persistent) do not show any antibacterial activity. These observations

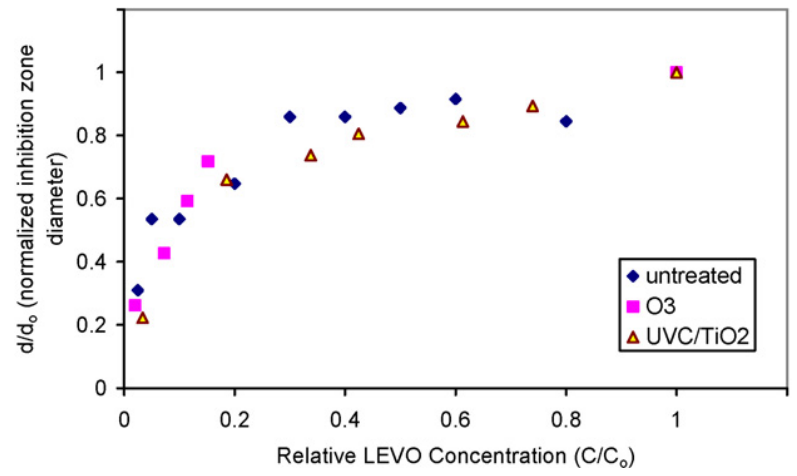

Fig. 9. Comparison of antibacterial activity effect of treated and untreated solutions. Untreated case contains only LEVO in solution. Ozone and $\mathrm{UVC} / \mathrm{TiO}_{2}$ treated cases also contain their oxidation products as well as residual concentration of LEVO plotted as $C / C_{\mathrm{o}}$ (photocatalysis conditions: $C_{\mathrm{o}}=20 \mathrm{mg} / \mathrm{L}, C_{\mathrm{TiO}_{2}}=0.2 \mathrm{~g} / \mathrm{L}$ ).

were also demonstrated by De Witte et al. [25] for ozonation and by Paul et al. [29] for UVA photocatalysis. De Witte et al. [25] showed that residual antibacterial activity of ciprofloxacin after ozonation towards $E$. coli and $P$. Fluorescens to be mainly determined by the target compound degradation rate. Paul et al. [29] showed that antibacterial activity correlated well with the residual ciprofloxacin concentration and antibacterial activity of reaction products to appear to be insignificant against $E$. coli during UVA photocatalysis.

\section{Conclusion}

Comparison of performances of ozonation and photocatalysis under UVC radiation for removal of LEVO was reported for the first time. Both methods ensured removal of the target compound below the detection limit $(200 \mu \mathrm{g} / \mathrm{L})$. A transferred ozone dose of $20.5 \mathrm{mg} / \mathrm{L}$ was found to completely remove LEVO corresponding to a half-life time of only $6 \mathrm{~s}$. Only $35 \%$ of LEVO was removed by direct photolysis after $120 \mathrm{~min}$ of UVC radiation $(254 \mathrm{~nm})$. The removal of LEVO was enhanced in presence of $\mathrm{TiO}_{2}$, suggesting that the oxidizing species generated during photocatalysis are effective towards oxidation of LEVO. At 120 min of irradiation $97 \%$ of LEVO was removed and it was no longer detected at $180 \mathrm{~min}$ of irradiation. Ozonation products detected by HPLC were shown to be more persistent than the products observed during photocatalysis as indicated by the products HPLC peak area profiles and the respective COD removals obtained. Hydroxyl radicals were shown to play a significant role in the removal of LEVO during photocatalysis but to have a minor influence of removal of LEVO during ozonation. The hydroxyl radicals were also shown to play a significant role in removing the transformation products generated during each treatment. This observation was also supported by the COD removal results obtained for a two-step process combining ozone and photocatalytic treatments during which the persistent ozonation products were removed during the second step treatment by photocatalysis.

Antibacterial activity was removed completely both by ozonation and photocatalysis indicating no formation of transformation products having antibacterial properties. These results indicate that both ozonation and photocatalysis are effective in removing LEVO however, COD results indicate that photocatalysis seems to have a higher mineralization efficiency. The results presented here provide strong evidence that removal of LEVO and its antibacterial activity in pure water is possible by ozonation and photocatalysis. Further investigation on removal of this compound in more complex matrices is necessary to assess the applicability of ozonation and photocatalysis as potential pre-treatment methods of hospital or industrial wastewaters, prior to their discharge into sewage 
systems and to evaluate the residual toxicity associated with transformation products. This approach would also help minimize the risk of increasing antibacterial resistance of microorganisms found in biological treatment systems. Also, since UVC radiation is commonly used as a disinfection method in various treatment facilities, this research also allows estimating the UV doses that would be required for elimination of antibacterial activity of pharmaceuticals during disinfection and confirm the possibility of enhanced benefits when coupled with $\mathrm{TiO}_{2}$ photocatalysis.

\section{Acknowledgments}

Authors would like to acknowledge the Natural Sciences and Engineering Research Council of Canada (NSERC) and Eugenie Ulmer Lamothe Chemical Engineering Fund (McGill University) for the financial support provided for this work.

\section{Appendix A. Supplementary data}

Supplementary data associated with this article can be found, in the online version, at doi:10.1016/j.cej.2012.02.016.

\section{References}

[1] B. Halling-Sørensen, S. Nors Nielsen, P.F. Lanzky, F. Ingerslev, H.C. Holten Lützhøft, S.E. Jørgensen, Occurrence, fate and effects of pharmaceutical substances in the environment - a review, Chemosphere 36 (1998) 357-393.

[2] K. Kümmerer, Significance of antibiotics in the environment, J. Antimicrob. Chemother. 52 (2003) 5-7.

[3] F. Baquero, J.-L. Martínez, R. Cantón, Antibiotics and antibiotic resistance in water environments, Curr. Opin. Biotechnol. 19 (2008) 260-265.

[4] G.A. Jacoby, Mechanisms of resistance to quinolones, Clin. Infect. Dis. 41 (2005) S120-S126.

[5] L.-H. Yang, G.-G. Ying, H.-C. Su, J.L. Stauber, M.S. Adams, M.T. Binet, Growthinhibiting effects of 12 antibacterial agents and their mixtures on the freshwater microalga Pseudokirchneriella subcapitata, Environ. Toxicol. Chem. 27 (2008) 1201-1208.

[6] M. Ferech, S. Coenen, S. Malhotra-Kumar, K. Dvorakova, E. Hendrickx, C. Suetens, H. Goossens, o.b.o.t.E.P. Group, European Surveillance of Antimicrobial Consumption (ESAC): outpatient quinolone use in Europe, J. Antimicrob. Chemother. 58 (2006) 423-427.

[7] H.A. Duong, N.H. Pham, H.T. Nguyen, T.T. Hoang, H.V. Pham, V.C. Pham, M. Berg, W. Giger, A.C. Alder, Occurrence, fate and antibiotic resistance of fluoroquinolone antibacterials in hospital wastewaters in Hanoi, Vietnam, Chemosphere 72 (2008) 968-973.

[8] E.M. Golet, I. Xifra, H. Siegrist, A.C. Alder, W. Giger, Environmental exposure assessment of fluoroquinolone antibacterial agents from sewage to soil, Environ. Sci. Technol. 37 (2003) 3243-3249.

[9] D.W. Kolpin, E.T. Furlong, M.T. Meyer, E.M. Thurman, S.D. Zaugg, L.B. Barber, H.T. Buxton, Pharmaceuticals, hormones, and other organic wastewater contaminants in U.S. streams, 1999-2000: a national reconnaissance, Environ. Sci. Technol. 36 (2002) 1202-1211.

[10] K. Kümmerer, A. Al-Ahmad, V. Mersch-Sundermann, Biodegradability of some antibiotics, elimination of the genotoxicity and affection of wastewater bacteria in a simple test, Chemosphere 40 (2000) 701-710.

[11] F. Baquero, Low-level antibacterial resistance: a gateway to clinical resistance, Drug Resist. Update 4 (2001) 93-105.

[12] K. Drlica, The mutant selection window and antimicrobial resistance, J. Antimicrob. Chemother. 52 (2003) 11-17.

[13] R. Andreozzi, M. Canterino, R. Marotta, N. Paxeus, Antibiotic removal from wastewaters: the ozonation of amoxicillin, J. Hazard. Mater. 122 (2005) 243-250.

[14] V. Yargeau, C. Leclair, Potential of ozonation for degradation of antibiotics in wastewater, Water Sci. Technol. 55 (2007) 321-326.

[15] V. Yargeau, C. Leclair, Impact of operating conditions on decomposition of antibiotics during ozonation: a review, Ozone Sci. Eng. 30 (2008) 175-188

[16] O. González, C. Sans, S. Esplugas, Sulfamethoxazole abatement by photoFenton: toxicity, inhibition and biodegradability assessment of intermediates, J. Hazard. Mater. 146 (2007) 459-464.

[17] R. Andreozzi, V. Caprio, R. Marotta, A. Radovnikovic, Ozonation and $\mathrm{H}_{2} \mathrm{O}_{2} / \mathrm{UV}$ treatment of clofibric acid in water: a kinetic investigation, J. Hazard. Mater. 103 (2003) 233-246.
[18] T.E. Doll, F.H. Frimmel, Fate of pharmaceuticals - photodegradation by simulated solar UV-light, Chemosphere 52 (2003) 1757-1769.

[19] R. Palominos, J. Freer, M.A. Mondaca, H.D. Mansilla, Evidence for hole participation during the photocatalytic oxidation of the antibiotic flumequine, $\mathrm{J}$. Photochem. Photobiol. A 193 (2008) 139-145.

[20] L. Rizzo, S. Meric, D. Kassinos, M. Guida, F. Russo, V. Belgiorno, Degradation of diclofenac by $\mathrm{TiO}_{2}$ photocatalysis: UV absorbance kinetics and process evaluation through a set of toxicity bioassays, Water Res. 43 (2009) 979-988.

[21] V. Yargeau, J.C. Huot, A. Rodayan, L. Rouleau, R. Roy, R.L. Leask, Impact of degradation products of sulfamethoxazole on mammalian cultured cells, Environ. Toxicol. 23 (2008) 492-498.

[22] T. An, H. Yang, G. Li, W. Song, W.J. Cooper, X. Nie, Kinetics and mechanism of advanced oxidation processes (AOPs) in degradation of ciprofloxacin in water, Appl. Catal. B 94 (2010) 288-294.

[23] E. De Bel, J. Dewulf, B.D. Witte, H. Van Langenhove, C. Janssen, Influence of pH on the sonolysis of ciprofloxacin: biodegradability, ecotoxicity and antibiotic activity of its degradation products, Chemosphere 77 (2009) 291-295

[24] B. De Witte, J. Dewulf, K. Demeestere, H. Van Langenhove, Ozonation and advanced oxidation by the peroxone process of ciprofloxacin in water, J. Hazard. Mater. 161 (2009) 701-708.

[25] B. De Witte, H. Van Langenhove, K. Demeestere, K. Saerens, P. De Wispelaere, J. Dewulf, Ciprofloxacin ozonation in hospital wastewater treatment plant effluent: effect of $\mathrm{pH}$ and $\mathrm{H}_{2} \mathrm{O}_{2}$, Chemosphere 78 (2010) 1142-1147.

[26] T.G. Vasconcelos, D.M. Henriques, A. König, A.F. Martins, K. Kümmerer, Photodegradation of the antimicrobial ciprofloxacin at high $\mathrm{pH}$ : identification and biodegradability assessment of the primary by-products, Chemosphere 76 (2009) 487-493.

[27] E. Hapeshi, A. Achilleos, M.I. Vasquez, C. Michael, N.P. Xekoukoulotakis, D. Mantzavinos, D. Kassinos, Drugs degrading photocatalytically: kinetics and mechanisms of ofloxacin and atenolol removal on titania suspensions, Water Res. 44 (2010) 1737-1746.

[28] I. Michael, E. Hapeshi, C. Michael, D. Fatta-Kassinos, Solar Fenton and solar $\mathrm{TiO}_{2}$ catalytic treatment of ofloxacin in secondary treated effluents: evaluation of operational and kinetic parameters, Water Res. 44 (2010) 5450-5462.

[29] T. Paul, M.C. Dodd, T.J. Strathmann, Photolytic and photocatalytic decomposition of aqueous ciprofloxacin: transformation products and residual antibacterial activity, Water Res. 44 (2010) 3121-3132.

[30] T. Paul, P.L. Miller, T.J. Strathmann, Visible-light-mediated $\mathrm{TiO}_{2}$ photocatalysis of fluoroquinolone antibacterial agents, Environ. Sci. Technol. 41 (2007) 4720-4727.

[31] B.D. Witte, H.V. Langenhove, K. Hemelsoet, K. Demeestere, P.D. Wispelaere, V. Van Speybroeck, J. Dewulf, Levofloxacin ozonation in water: rate determining process parameters and reaction pathway elucidation, Chemosphere 76 (2009) 683-689.

[32] M.W. Lam, S.A. Mabury, Photodegradation of the pharmaceuticals atorvastatin, carbamazepine, levofloxacin, and sulfamethoxazole in natural waters, Aquat. Sci. 67 (2005) 177-188.

[33] M.W. Lam, C.J. Young, R.A. Brain, D.J. Johnson, M.A. Hanson, C.J. Wilson, S.M. Richards, K.R. Solomon, S.A. Mabury, Aquatic persistence of eight pharmaceuticals in a microcosm study, Environ. Toxicol. Chem. 23 (2004) 1431-1440.

[34] T. An, H. Yang, W. Song, G. Li, H. Luo, W.J. Cooper, Mechanistic considerations for the advanced oxidation treatment of fluoroquinolone pharmaceutical compounds using $\mathrm{TiO}_{2}$ heterogeneous catalysis, J. Phys. Chem. A 114 (2010) 2569-2575.

[35] A. Rodayan, R. Roy, V. Yargeau, Oxidation products of sulfamethoxazole in ozonated secondary effluent, J. Hazard. Mater. 177 (2010) 237-243.

[36] D. Nasuhoglu, V. Yargeau, D. Berk, Photo-removal of sulfamethoxazole (SMX) by photolytic and photocatalytic processes in a batch reactor under UV-C radiation ([lambda]max = 254 nm), J. Hazard. Mater. 186 (2011) 67-75.

[37] Y. Chen, S. Yang, K. Wang, L. Lou, Role of primary active species and $\mathrm{TiO}_{2}$ surface characteristic in UV-illuminated photodegradation of Acid Orange 7, J. Photochem. Photobiol. A 172 (2005) 47-54.

[38] U.I. Gaya, A.H. Abdullah, Heterogeneous photocatalytic degradation of organic contaminants over titanium dioxide: a review of fundamentals, progress and problems, J. Photochem. Photobiol. C 9 (2008) 1-12.

[39] J.M. Herrmann, Heterogeneous photocatalysis: state of the art and present applications In honor of Pr. R.L. Burwell Jr. (1912-2003), Former Head of Ipatieff Laboratories, Northwestern University, Evanston (Ill.), Top. Catal. 34 (2005) 49-65.

[40] X. Van Doorslaer, P.M. Heynderickx, K. Demeestere, K. Debevere, H. Van Langenhove, J. Dewulf, $\mathrm{TiO}_{2}$ mediated heterogeneous photocatalytic degradation of moxifloxacin: operational variables and scavenger study, Appl. Catal. B 111-112 (2012) 150-156.

[41] M.C. Dodd, M.-O. Buffle, U. von Gunten, Oxidation of antibacterial molecules by aqueous ozone: moiety-specific reaction kinetics and application to ozonebased wastewater treatment, Environ. Sci. Technol. 40 (2006) 1969-1977.

[42] T.G. Vasconcelos, K. Kümmerer, D.M. Henriques, A.F. Martins, Ciprofloxacin in hospital effluent: degradation by ozone and photoprocesses, J. Hazard. Mater. 169 (2009) 1154-1158. 